\title{
Article \\ The Influence of the Ratio of Au and Pt Nanoparticles in Ternary Composites with $\mathrm{TiO}_{2}$
}

\author{
Boglárka Hampel ${ }^{1,2}$, Lucian Baia ${ }^{2,3}{ }^{\mathbb{D}}$, Klara Hernadi ${ }^{1,4, *(\mathbb{D})}$ and Zsolt Pap ${ }^{1,2,3, *}$ \\ 1 Department of Applied and Environmental Chemistry, University of Szeged, Rerrich Béla sqr. 1, \\ HU-6720 Szeged, Hungary; hampelboglarka@chem.u-szeged.hu \\ 2 Nanostructured Materials and Bio-Nano-Interfaces Center, Institute for Interdisciplinary Research on \\ Bio-Nano-Sciences, Babes Bolyai University, Treboniu Laurian str. 42, RO-400271 Cluj-Napoca, Romania; \\ lucian.baia@phys.ubbcluj.ro \\ 3 Faculty of Physics, Babes Bolyai University, Mihail Kogalniceanu str. 1, RO-400084 Cluj-Napoca, Romania \\ 4 Institute of Physical Metallurgy, Metal Forming and Nanotechnology, University of Miskolc, \\ HU-3515 Miskolc-Egyetemváros, Hungary \\ * Correspondence: hernadi@chem.u-szeged.hu (K.H.); pzsolt@chem.u-szeged.hu (Z.P.)
}

Citation: Hampel, B.; Baia, L.;

Hernadi, K.; Pap, Z. The Influence of the Ratio of $\mathrm{Au}$ and Pt Nanoparticles in Ternary Composites with $\mathrm{TiO}_{2}$ Metals 2021, 11, 628 .

https://doi.org/10.3390/

met11040628

Academic Editors: Jan Vrestal, Leonid M. Kustov and Isabel Duarte

Received: 23 February 2021

Accepted: 2 April 2021

Published: 13 April 2021

Publisher's Note: MDPI stays neutral with regard to jurisdictional claims in published maps and institutional affiliations.

Copyright: (c) 2021 by the authors. Licensee MDPI, Basel, Switzerland. This article is an open access article distributed under the terms and conditions of the Creative Commons Attribution (CC BY) license (https:// creativecommons.org/licenses/by/ $4.0 /)$.

\begin{abstract}
In the present work, ternary composites were synthesized from commercial titanias (Evonik Aeroxide P25, Aldrich anatase-AA and Aldrich rutile-AR) and two noble metals (gold and platinum). This research focuses on the composition of the photocatalysts, especially on the noble metals. The ratio between the noble metals varies from 0.25 to $0.75 \%$ in each composite for each noble metal. Transmission electron microscopy (TEM), X-ray diffraction (XRD) and diffuse reflectance spectroscopy (DRS) measurements were carried out to investigate the structural and optical properties. From the TEM, it can be observed that the particle sizes of the noble metals were between 1 and $4 \mathrm{~nm}$, while the (anatase and rutile) crystals of P25 were 20-40 nm. The XRD showed that the semiconductors' composition remained unchanged during/after the deposition of noble metal nanoparticles. By the DRS measurements, using the Kubelka-Munk equation, it can be concluded that the deposition of the noble metal nanoparticles resulted the decrease of the bandgap energies of the titanias. The photocatalytic activity was investigated under the irradiation of UV light. Oxalic acid and salicylic acid were used as model pollutants. The hydrogen production capacity was investigated as well, where the sacrificial agent was oxalic acid, and UV irradiation was used.
\end{abstract}

Keywords: photocatalysis; commercial titania; noble metal nanoparticles; composites; UV light

\section{Introduction}

Materials at nanometer scale show different chemical and physical properties than their macroscopic forms, which are advantageous for many current research fields. Nanotechnology is the study and application of these materials, which can be used in many areas, such as in medicine [1], electronics [2], fuel cells [3], cosmetics and textile industry [4], food industry [5], sensors [6], environmental applications [7], etc.

Among many environmental applications, wastewater treatment is a very important process, where photocatalysis emerges as a viable alternative [8]. Among the nanoscaled semiconductor materials $\left(\mathrm{Cu}_{2} \mathrm{O}\right.$ [9], $\mathrm{WO}_{3}$ [10], $\mathrm{ZnO}$ [11], BiOX [12], etc.) titania photocatalysts are the most studied ones [13]. The efficiency of these semiconductors can be enhanced by creating composites [14]. These nanostructures, containing semiconductors and metal nanoparticles, were synthesized and used so far. It was found that the composition of the composites had a major effect on the overall photocatalytic efficiency [15].

In photocatalysis, composite systems are widely used because of their many advantageous properties. For example, metal nanoparticles deposited on the surface of a semiconductor can accelerate the electron-hole separation [16]; also, charge distribution greatly influences the photocatalytic activity [17]. For instance, the formation of composites from 
$\mathrm{TiO}_{2}$ with graphene oxide can expand the light absorption range [18], or with carbon aerogel, the photocatalytic activity can be enhanced [19]. Bimetallic composites can result in a hypsochromic shift [20].

Many ternary composites from semiconductor and (noble) metals were fabricated and studied by now [20-23]. The conclusions are interesting from the point of view of the composition of these composites. It was found that the best photocatalytic activity was achieved when less than $5 \%$ is of noble metal was present on the semiconductors' surface $[20,21]$. When $\mathrm{Au}$ and $\mathrm{Ag}$ metals were used for the preparation of ternary composites, the ratio of them is also important: 1:3 [22] or 1:4 [23] metal ratio was used.

Bi-and trimetallic systems can be used for many applications. They have catalytic activity for thermal decomposition of ammonium perchlorate [24], oxygen reduction by electrocatalysis [25] or degradation of methylene blue [26].

In a previously reported study [27], ternary composites were prepared and tested. These materials were made of three commercial titanias (Evonik Aeroxide P25 or Aldrich anatase or Aldrich rutile) and two noble metals (gold and platinum). The composition of the photocatalysts was $99 \mathrm{wt} \% \mathrm{TiO}_{2}$ and $1 \mathrm{wt} \%$ noble metal particles. In every case, the ratio of the noble metals was 1:1, and that was the starting point for the sequel of this study. The ratio of the two noble metals is a crucial parameter in the determination of photocatalytic activity.

That is why the aim of the present research is the preparation of ternary composites (containing $\mathrm{TiO}_{2}$, Au and Pt nanoparticles) by changing the composition of the materials compared to the previous research. Titanium dioxide remained at $99 \mathrm{wt} \%$, and the weight ratio of the noble metals was changed to $0.25-0.75 \%$ and $0.75-0.25 \%$, respectively. The photocatalytic activity - the degradation of oxalic- and salicylic acid and hydrogen production-and morphological and structural properties were studied considering the ratio between the two noble metals.

\section{Materials and Methods}

For the experiments, the following materials were used without further purification: Evonik Aeroxide P25 (89 $\mathrm{wt} \%$ anatase, $11 \mathrm{wt} \%$ rutile; $99.5 \%$ trace metal basis; $25-40 \mathrm{~nm}$ primary particle size and $25 \mathrm{~m}^{2} / \mathrm{g}$ specific surface area, Essen, Germany), Aldrich anatase $\left(99.7 \%\right.$ trace metal basis; $80 \mathrm{~nm}$ primary particle size and $9.7 \mathrm{~m}^{2} / \mathrm{g}$ specific surface area, Schnelldorf, Germany) and Aldrich Rutile (99.995\% trace metals basis; 150-200 nm primary particle size and $2.9 \mathrm{~m}^{2} / \mathrm{g}$ specific surface area, Schnelldorf, Germany)—will be henceforward denoted as P25, AA and AR, respectively. The AA and AR nanopowders were purchased from Sigma-Aldrich, the P25 from Evonik Industries. The gold precursor was $\mathrm{HAuCl}_{4} \cdot 4 \mathrm{H}_{2} \mathrm{O}(99.99 \%$ trace metal basis, Sigma-Aldrich, Schnelldorf, Germany, and it was used as a $12.7 \mathrm{mM}$ aqueous solution, while the platinum precursor was $\mathrm{H}_{2} \mathrm{PtCl}_{6} \cdot 6 \mathrm{H}_{2} \mathrm{O}$ (37.5\% Pt basis; Merck, Darmstadt, Germany) and it was used as an $11.87 \mathrm{mM}$ solution. Trisodium citrate $\left(\mathrm{Na}_{3} \mathrm{C}_{3} \mathrm{H}_{5} \mathrm{O}(\mathrm{COO})_{3}\right)(99.99 \%$ purity; Alfa-Aesar, Karlsruhe, Germany) was used as a solution of $0.063 \mathrm{mM}$ for the stabilization of the noble metal particles size. For the reduction of the noble metal precursors, sodium borohydride $\left(\mathrm{NaBH}_{4} ; 96 \%\right.$ purity; acquired from Merck, Darmstadt, Germany) was used as a solution of $0.15 \mathrm{M}$. During the assessment of the photocatalytic activity and the hydrogen production capacity, high purity oxalic acid (99.99\%, Spektrum 3D, Debrecen, Hungary) and salicylic acid (99.9\%, Europharm, Bucharest, Romania) was used as 5 and $50 \mathrm{mM}$ (oxalic acid) and $0.5 \mathrm{mM}$ (salicylic acid) solution, respectively.

The synthesis of the ternary composites was the same as previously reported [27], and it is presented in Figure 1. 


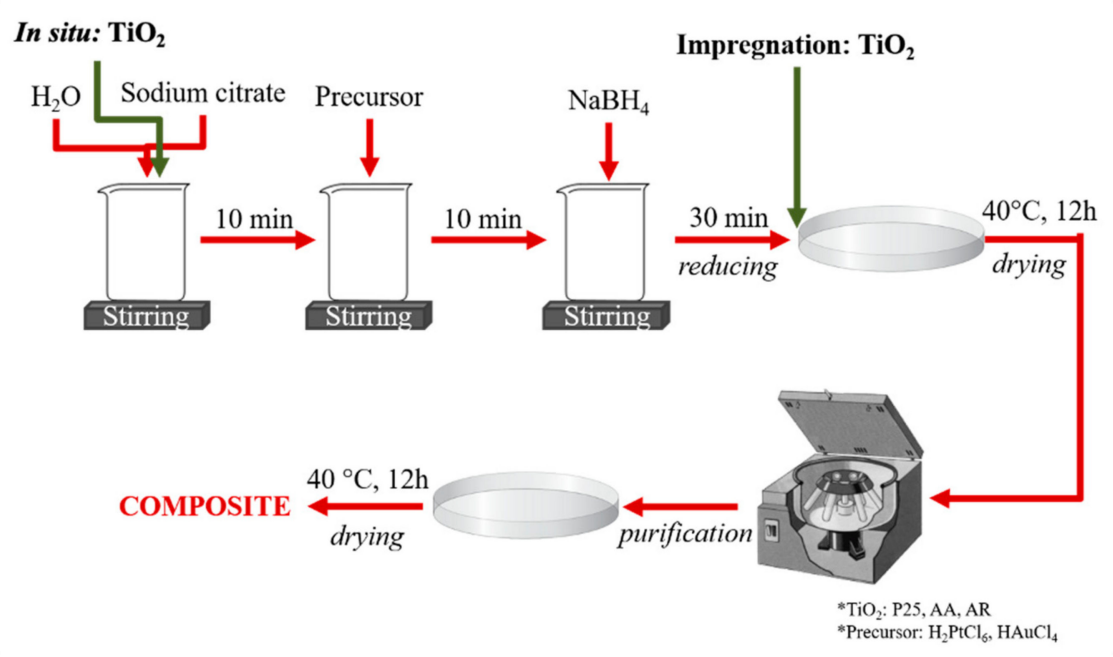

Figure 1. Synthesis and purification of the nanocomposites by the chemical reduction of $\mathrm{Au}$ and $\mathrm{Pt}$, using in situ and impregnation as possible pathways of the reaction.

As for the synthesis strategies, two methods were used: in situ reduction and impregnation [28]. In all cases, the total noble metal content was $1 \mathrm{wt} \%$. As it can be seen in Figure 1, in the case of in situ reductions, titanium dioxide (P25, AA or AR) was added before the reduction of the noble metals, while in the case of impregnation, titania was added after the reduction of the $\mathrm{Au}$ and $\mathrm{Pt}$.

These noble metal nanoparticles were formed by the following reactions:

$$
\begin{gathered}
2 \mathrm{HAuCl}_{4}+4 \mathrm{NaBH}_{4} \rightarrow 2 \mathrm{Au}^{\circ}+4 \mathrm{HCl}+4 \mathrm{NaCl}+4 \mathrm{BH}_{3}+\mathrm{H}_{2} \\
\mathrm{H}_{2} \mathrm{PtCl}_{6}+3 \mathrm{NaBH}_{4} \rightarrow \mathrm{Pt}^{\circ}+3 \mathrm{HCl}+3 \mathrm{NaCl}+3 \mathrm{BH}_{3}+\mathrm{H}_{2}
\end{gathered}
$$

The only exception from the previous study was the composition: the ratio of $\mathrm{Au}$ and $\mathrm{Pt}$ nanoparticles was changed. The synthesis of the noble metals was carried out by a simple chemical reduction, which is demonstrated in the (1) and (2) reaction equations. The precursors were $\mathrm{H}_{2} \mathrm{PtCl}_{6}$ and $\mathrm{HAuCl}_{4}$, the reducing agent was $\mathrm{NaBH}_{4}$ (freshly prepared), and trisodium citrate solution was added to stabilize the size of the Au and Pt nanoparticles.

Two reduction approaches were used during the synthesis: sequential and simultaneous for both reduction methods (in situ and impregnation).

As already stated before, the composites consisted of $99 \mathrm{wt} \% \mathrm{TiO}_{2}$ and $1 \mathrm{wt} \%$ noble metals:

- $0.25 \%$ Au and $0.75 \% \mathrm{Pt}$;

- $0.75 \%$ Au and $0.25 \% \mathrm{Pt}$;

- $1 \%$ Au and $0 \% \mathrm{Pt}$-reference sample;

- $0 \% \mathrm{Au}$ and $1 \% \mathrm{Pt}$-reference sample.

The previous results [27] of oxalic acid degradation and hydrogen production were compared. The samples that most efficiently ( $100 \%$ conversion and maximum reaction rate) decomposed oxalic acid or samples that produced the most hydrogen were selected. From each series of photocatalysts made with the best in situ and impregnation, the composition of the composites was changed.

The nomenclature of the samples was defined as follows: the abbreviation of the titania photocatalyst + "_is" for the samples obtained by in situ reductions, or "_im" for the samples made with impregnation. This was completed with: " $\mathrm{Au} / \mathrm{Pt}^{\prime}$ when $\mathrm{Au}$ was reduced before $\mathrm{Pt}$; "Pt/ $\mathrm{Au}$ " when $\mathrm{Pt}$ was reduced before $\mathrm{Au}$; or "Au\&Pt" when both noble metals were obtained simultaneously. Additionally, in front of the $\mathrm{Au}$ or $\mathrm{Pt}$, the numbers 25 and 75 stated the relative ratio of the noble metals. A relevant example is the case of AA_im_25Pt\&75Au, which was obtained from Aldrich anatase (AA), $0.25 \% \mathrm{Pt}$ and $0.75 \%$ $\mathrm{Pt}$ were reduced simultaneously ( $\mathrm{Au \& Pt}$ ) using the impregnation method (im). 
For the characterization of the obtained materials, the following methods and instrumentation were used:

The crystalline phase composition and mean primary crystallite size of the photocatalysts were determined by X-ray diffraction (XRD) with a Rigaku diffractometer (Neu-Isenburg, Germany)using Cu-K $\alpha$ radiation $(\lambda=1.5406 \AA)$ equipped with a graphite monochromator. The primary crystallite size of the commercial semiconductors was evaluated using the well-known Scherrer equation [29].

UV-vis reflectance spectra (DRS) of the samples $(\lambda=300-800 \mathrm{~nm})$ were registered by using JASCO-V650 spectrophotometer (Portland, OR, USA)with an integration sphere (ILV-724). The indirect bandgap of the photocatalysts was determined via the KubelkaMunk method.

Transmission electron microscopy and high-resolution transmission electron microscopy (TEM/HRTEM) micrographs were obtained with an FEI Tecnai F20 field emission highresolution transmission electron microscope (Hillsboro, OR, USA), operating at an accelerating voltage of $200 \mathrm{kV}$ and equipped with an Eagle 4k CCD camera (Hillsboro, OR, USA).

For the $\mathrm{H}_{2}$ production measurements, the freshly prepared, washed catalyst was dispersed in $50 \mathrm{mM}$ oxalic acid solution. An ultrasonic bath was used to distribute the catalyst more efficiently. Then the system was stirred for $15 \mathrm{~min}$ in the dark for adsorption to occur. Subsequently, it was poured into a glass reactor (total volume: $150 \mathrm{~mL}$ ), and it was irradiated with $10 \times 15 \mathrm{~W}$ UV fluorescent lamps $\left(\lambda_{\max }=365 \mathrm{~nm}\right.$, LightTech Kft., Budapest, Hungary). The well-homogenized suspension $\left(c_{\text {catalyst }}=1 \mathrm{~g} \cdot \mathrm{L}^{-1}\right)$ was purged with $\mathrm{N}_{2}\left(99.995 \%\right.$, Messer Kft., Budapest, Hungary) at a flow rate of $50 \mathrm{~mL} \cdot \mathrm{min}^{-1}$ to ensure $\mathrm{O}_{2}$-free conditions. The reactor was connected through a PTFE tube to a Hewlett Packard 5890 gas chromatograph (GC) fitted with a $5 \AA$ molecular sieve column and a thermal conductivity detector (Hewlett-Packard, Palo Alto, CA, USA). Samples were taken from the gas flow with a $2 \mathrm{~mL}$ sampling valve every $10 \mathrm{~min}$ in the first hour of the experiment and every $20 \mathrm{~min}$ in the second hour. The rate of $\mathrm{H}_{2}$ evolution was calculated using the calibration (carried out with certified 5:95 $\mathrm{H}_{2}: \mathrm{N}_{2}$ gas) and the applied $\mathrm{N}_{2}$ flow rate.

The UV decomposition of oxalic acid was carried out under the same conditions as the $\mathrm{H}_{2}$ production measurements, except that the system was irradiated with $6 \times 6 \mathrm{~W}$ fluorescent lamps, and $5 \mathrm{mM}$ of oxalic acid was used. Liquid samples were taken from the suspension at specific time intervals during the reaction. After the centrifugation and filtration (with a Whatman Anotop $250.02 \mu \mathrm{m}$ syringe filter) of the samples, the residual oxalic acid concentration was measured using high-performance liquid chromatography (HPLC). This was performed on a Merck Hitachi device fitted with an L-4250 UV-vis detector (Merck KGaA, Darmstadt, Germany) and a GROM Resin ZH $8 \mu$ m column. No photolysis of oxalic acid was detected under these conditions. The UV decomposition of salicylic acid was carried out under the same conditions as the decomposition of oxalic acid. The only exception was that the salicylic acid solution was $0.5 \mathrm{mM}$. The concentration of the salicylic acid was followed with a JASCO-V650 spectrophotometer (Portland, OR, USA). In all the cases, the conversion was, as shown in Equation (3):

$$
\text { Degradation }(\%)=\frac{\text { Concentration of the pollutant at a given time }}{\text { Concentration of the pollutant before the experiment }} \times 100
$$

It should be noted that both the used noble metals and base photocatalysts were known to be stable during photocatalytic reactions. As randomly chosen samples were retested in the photocatalytic experiments, the same activity values were registered within $+/-5 \%$.

\section{Results and Discussion}

\subsection{X-ray Diffraction}

As a first step of the characterization process, the mean crystallite size and phase composition were evaluated using diffraction patterns. This measurement was performed for the purpose of verifying the structure of the base photocatalysts. 
The composition of the semiconductors remained unchanged during/after the deposition of noble metal nanoparticles, as follows: Aldrich anatase (AA) contained only anatase crystal phase $(\approx 80-100 \mathrm{~nm}$, JCPDS card no. 21-1272 [30]), Aldrich rutile (AR) contained mainly rutile phase with larger particles $(\approx 300 \mathrm{~nm}$, JCPDS card no. 21-1276 [30]) and a small amount of anatase $(\leq 4 \mathrm{wt} \%)$ as well, while Evonik Aeroxide P25 (P25) contained anatase and rutile ( $89 \mathrm{wt} \%, \approx 25 \mathrm{~nm}$ vs. $11 \mathrm{wt} \%, \approx 40 \mathrm{~nm}$, Figure 2 ). It must be mentioned that the noble metal nanoparticles were not detectible, as their concentration was lower than the detection limit of the instrument and some of the most intensive diffraction peaks (e.g., the one at 38 ( $2 \theta$ degrees) for Au, JCPDS card no. 01-1174) were covered by the triplet signal of anatase in the same region.

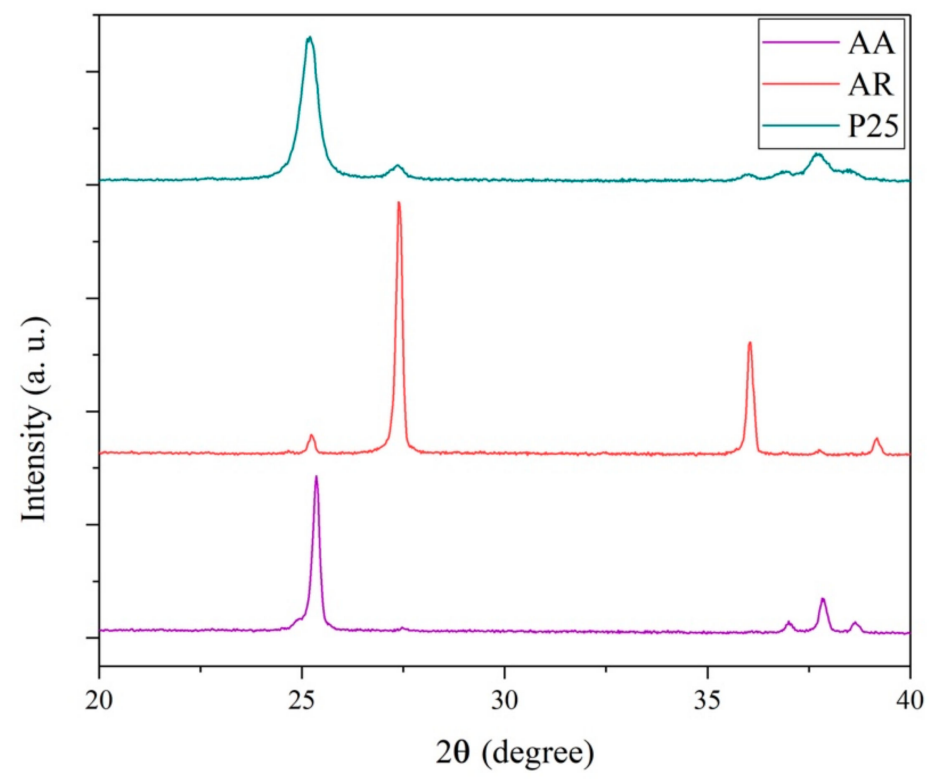

Figure 2. The XRD patterns of the commercial photocatalysts, showing that the composition of the semiconductor remained unchanged during/after the deposition of noble metal nanoparticles.

\subsection{Transmission Electron Microscopy (TEM)}

The morphological characteristics of the composites were investigated with transmission electron microscopy. During this measurement, only the P25-based composites were examined because the particle sizes of the AA and AR were much larger (AA-150 nm, AR-200 nm) than the noble metal nanoparticles, which would not be noticeable next to them [31]. The noble metals' particle size values were between 1 and $4 \mathrm{~nm}$, while the anatase and rutile crystals' size in P25 was 20-40 nm [32], and they showed no specific morphology (polyhedral and spherical nanocrystals were detected). The gold and platinum particles were small spheres that were randomly located on the surface of $\mathrm{TiO}_{2}$. There is no significant difference between the TEM recordings of the samples prepared by using different methods, the noble metal nanoparticles appear, but the Au cannot be differentiated from Pt. That is why Figure 3 presents the TEM and HRTEM micrographs of P25_is-25Au/75 Pt only.

Additionally, the size distribution of the noble metal nanoparticles was carried out to certify if the size estimations were correct. Figure 4 proves that the obtained size of $\mathrm{Au}$ and $\mathrm{Pt}$ nanoparticles was between 1 and $4 \mathrm{~nm}$, with a dominance of $3.5 \mathrm{~nm}$. 


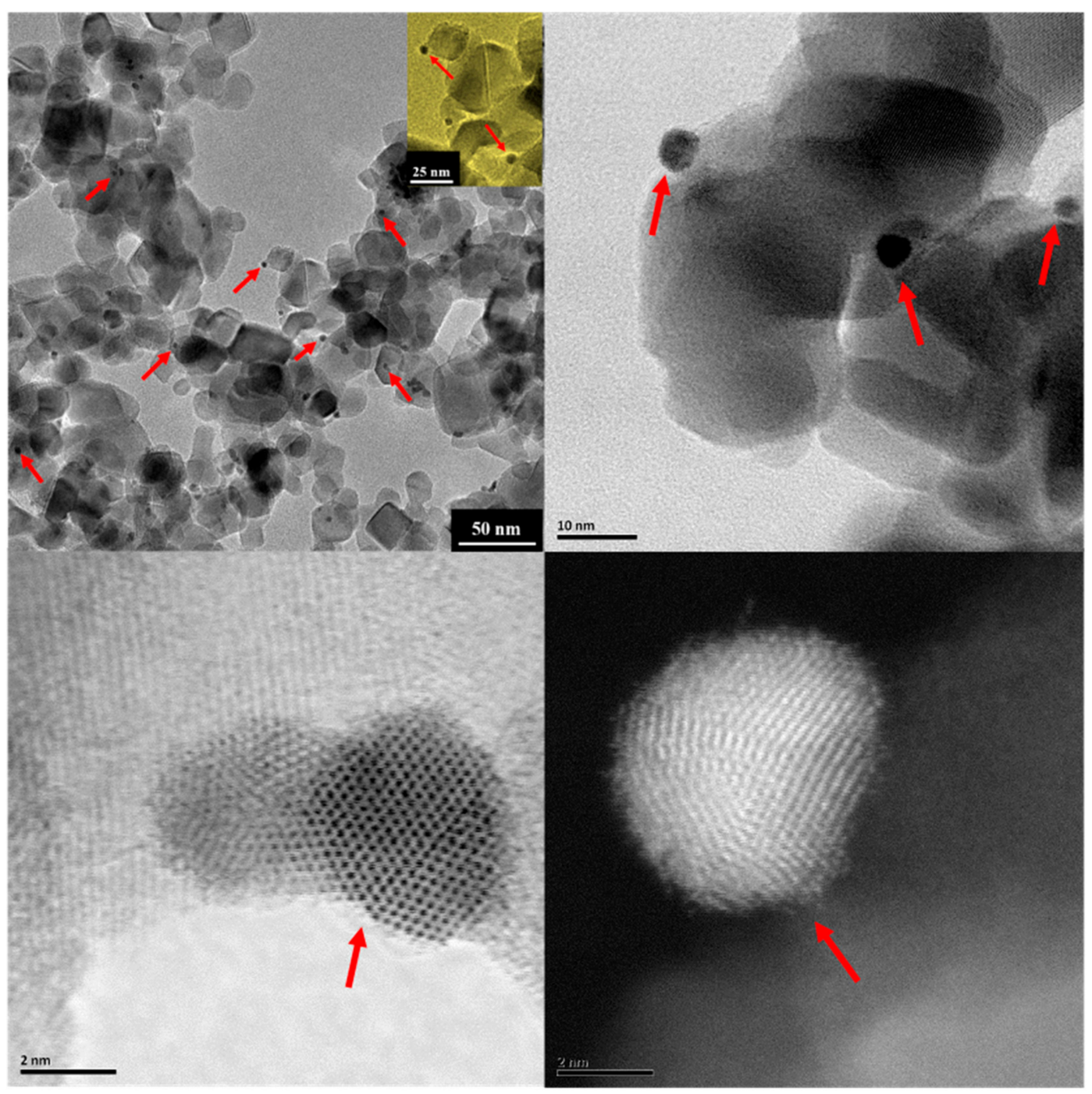

Figure 3. TEM and HRTEM micrograph of P25_is-25Au/75 Pt. The red arrows point to the noble metal nanoparticles, which have an average particle size of $1-4 \mathrm{~nm}$.

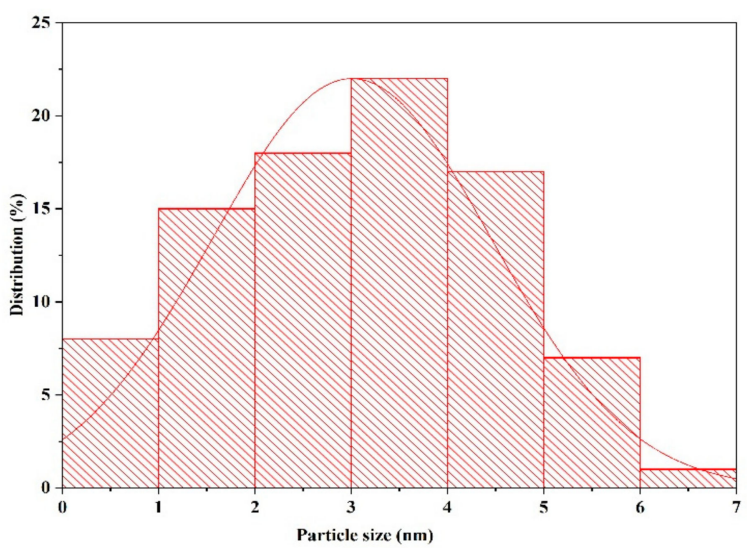

Figure 4. Noble metal nanoparticle size distribution of sample P25_is-25Au/75Pt, counting 100 nanoparticles. The distribution was nearly the same for all the materials. 


\subsection{Diffuse Reflectance Spectroscopy (DRS)}

The investigation of the optical properties of the composites is a very important step of the research because the light absorption properties can influence photocatalytic activity. Using the data obtained from the diffuse reflectance spectrometry, the bandgap energy values can be calculated with the Kubelka-Munk equation [33]. Table 1 summarizes the bandgap energy values in $\mathrm{eV}$ for all the catalysts investigated in this paper, while Figure 5 compares the composites' bandgap energy values based on the different titanias.

Table 1. The bandgap energies of the prepared composites [27].

\begin{tabular}{|c|c|c|c|c|c|c|}
\hline \multirow{2}{*}{$\begin{array}{c}\text { Reduction Approach } \\
\text { Synthesis strategy }\end{array}$} & \multicolumn{2}{|c|}{$\mathrm{Au} / \mathrm{Pt}(\mathrm{eV})$} & \multirow{2}{*}{$\begin{array}{c}\begin{array}{c}\mathbf{P t} / \mathrm{Au} \\
(\mathbf{e V})\end{array} \\
\text { P25_im }\end{array}$} & \multicolumn{3}{|c|}{$\mathrm{Au} \& \mathrm{Pt}(\mathrm{eV})$} \\
\hline & P25_is & AA_is & & $A A \_i m$ & $A R \_$is & AR_im \\
\hline $\begin{array}{c}0.25 \mathrm{Au} \\
0.75 \mathrm{Pt}\end{array}$ & 2.52 & 3.19 & 2.65 & 3.16 & 2.93 & 2.95 \\
\hline $\begin{array}{c}0.50 \mathrm{Au} \\
0.50 \mathrm{Pt}\end{array}$ & 2.57 & 3.13 & 2.67 & 3.17 & 2.89 & 2.91 [27] \\
\hline $\begin{array}{c}0.75 \mathrm{Au} \\
0.25 \mathrm{Pt}\end{array}$ & 2.61 & 3.12 & 2.76 & 3.16 & 2.94 & 2.96 \\
\hline $\mathrm{Au}$ & 2.47 & 3.15 & 2.22 & 3.17 & 2.88 & 2.88 \\
\hline \multirow[t]{3}{*}{$\mathbf{P t}$} & 2.75 & 3.19 & 2.54 & 3.15 & 2.82 & 2.93 \\
\hline & \multicolumn{2}{|c|}{$P 25$} & $A A$ & \multicolumn{3}{|c|}{$A R$} \\
\hline & \multicolumn{2}{|c|}{3.04} & 3.24 & \multicolumn{3}{|c|}{2.99} \\
\hline
\end{tabular}

The first and most important observation for all composites is that the deposition of the noble metal nanoparticles on the different $\mathrm{TiO}_{2}$ photocatalysts resulted in a decrease in the bandgap energies. Changing the ratio between the two noble metals got interesting results:

- For the P25-based catalysts lowering the ratio of Pt nanoparticles resulted in the decrease of the bandgap energy (from $3.04 \mathrm{eV}$ to $2.65 \mathrm{eV}$ for P25_im-75Pt/25Au, to $2.52 \mathrm{eV}$ for P25_is-25Au/75Pt);

- For AA-based photocatalysts obtained by impregnation, the decrease of the bandgap energy values cannot be linked with the ratio of the noble metals, while the differences between the values were also insignificant (the values vary from 3.15 to $3.17 \mathrm{eV}$ ). Using the in situ reductions, the same trend was observed as in the case of P25 (a decrease from $3.19 \mathrm{eV}$ to $3.12 \mathrm{eV}$ for AA_is-75Au/25Pt);

- When AR-based photocatalyst was investigated, the lowest bandgap energy was achieved when the ratio of the Au and Pt was 1:1 (2.89 eV for AR_is-Au\&Pt and $2.91 \mathrm{eV}$ for AR_im-Au\&Pt). 


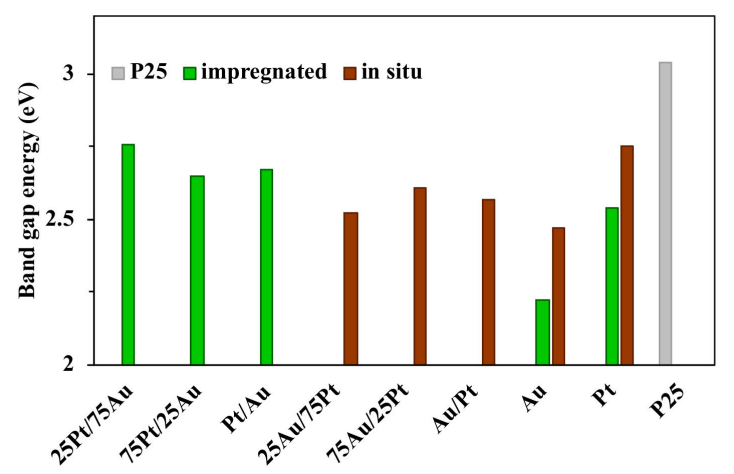

(a)

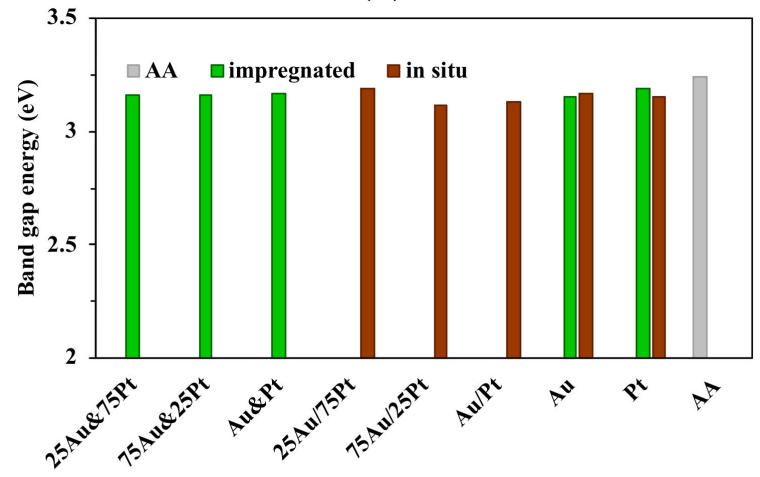

(b)

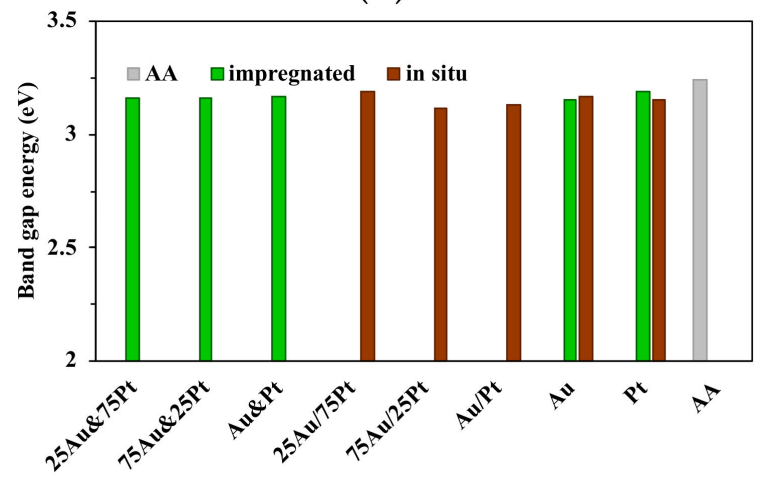

(c)

Figure 5. Comparison of the bandgap energy values of the composites based on the different titanias. (a) bandgap energies of the P25-based composites and P25, (b) bandgap energies of the AA-based composites and AA, (c) bandgap energies of the AR-based composites and AR.

In Figure 6, the DRS spectra of the composites are presented. As expected, the characteristic plasmonic band of the gold nanoparticles, around $550 \mathrm{~nm}$, are observable the same way as previously reported [27]. Looking at the spectra in Figure $6 \mathrm{~b}, \mathrm{c}$, when the two noble metals were reduced simultaneously, the plasmonic band of Au disappeared. In Figure 6b), the plasmonic bands of $\mathrm{Au}$ are noticeable only when $\mathrm{Au}$ is present in $0.75 \mathrm{wt} \%$. When the plasmonic band is not noticeable, the following cases may exist: the two noble metals form alloys, or they are arranged in a core-shell structure, where Pt covers the Au nanoparticles. It is worth highlighting that the appearance of the plasmonic band is the strongest in the case of P25-based composites because P25 has two crystal phases (anatase and rutile), which show high synergy in every aspect [34]. 


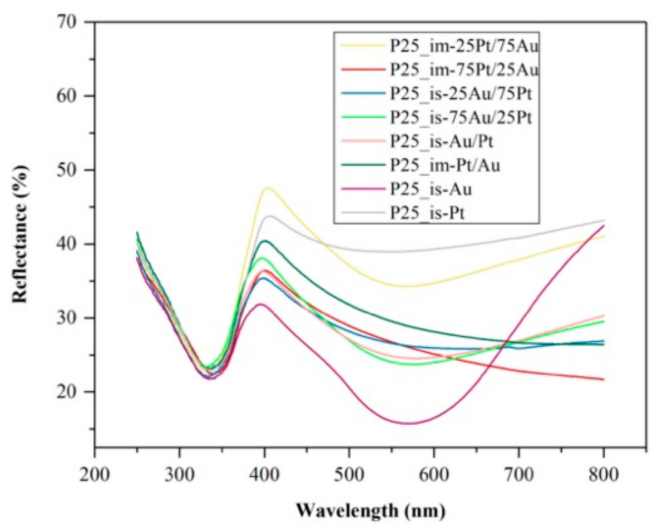

(a)

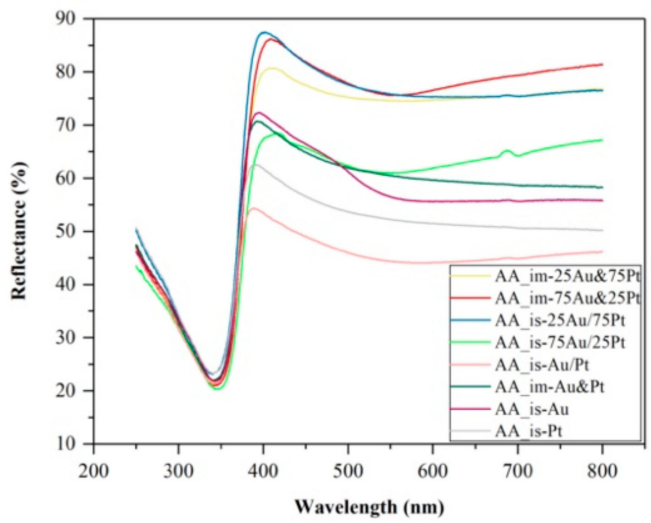

(b)

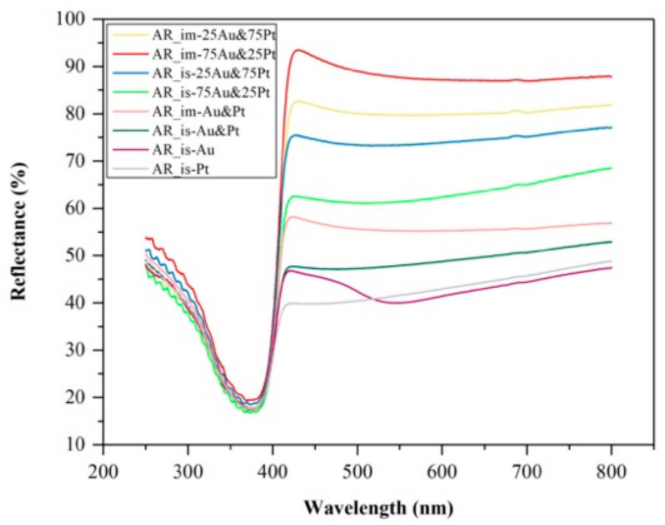

(c)

Figure 6. Diffuse reflectance spectroscopy (DRS) spectra of the (a) P25-based, (b) AA-based and (c) tAR-based composites.

\subsection{Photocatalytic Performance of the Composites}

\subsubsection{Photodegradation of Oxalic Acid}

From the P25-based composites, the ones made by using in situ reductions, the best performing sample was where the $\mathrm{Au}$ was reduced before $\mathrm{Pt}\left(\mathrm{P} 25 \_\mathrm{is}-\mathrm{Au} / \mathrm{Pt}\right)$. In this case, the noble metal ratio change did not increase the activity. After an hour, the best efficiency belonged to the composite containing $0.5 \% \mathrm{Au}$ and $0.5 \% \mathrm{Pt}(\approx 95 \%)$. The second-best catalyst was the composite with $0.25 \% \mathrm{Pt}$ and $0.75 \% \mathrm{Au}(\approx 84 \%)$. With the impregnation method, Au and Pt's ratio changed when the Pt was reduced first, then $\mathrm{Au}\left(\mathrm{P} 25 \_\mathrm{im}-\mathrm{Pt} / \mathrm{Au}\right)$. The composite achieved the best result with $0.25 \% \mathrm{Pt}$ and $0.75 \% \mathrm{Au}$ (after an hour $\approx 92 \%$ ).

For the composites containing AA, using the in situ method, the best result with $\approx 65 \%$ was shown by the sample in which $\mathrm{Au}$ and then $\mathrm{Pt}$ was reduced (AA_is- $\mathrm{Au} / \mathrm{Pt}$ ). 
After the noble metal ratio change, the best efficiency was observed with the Pt content reference catalyst and the composites with $0.5-0.5 \%$ noble metals achieving $\approx 65-70 \%$ conversion. After the change of the ratio between the noble metals, the one containing $0.25 \% \mathrm{Au}$ and $0.75 \% \mathrm{Pt}$ proved to be the next in line with a conversion of $\approx 53 \%$. Among the impregnated samples, the noble metal content change was made when both noble metals were reduced at the same time (AA_im-Au\&Pt). The concentration change did not improve in this case either, while the composite containing $0.5-0.5 \%$ noble metal sustained the best efficiency with $\mathrm{a} \approx 60 \%$ conversion. By changing the ratio, the composite containing $0.25 \% \mathrm{Au}$ and $0.75 \% \mathrm{Pt}$ had the best activity after the $0.5-0.5 \%$ catalyst $(\approx 35 \%)$.

For AR-based composites, the best results were achieved for both of the preparation methods (impregnation and in situ) when gold and platinum were simultaneously reduced (Au\&Pt). Following the change in concentration, in both cases, the best efficiencies were shown in the samples containing $0.25 \% \mathrm{Pt}$ and $0.75 \% \mathrm{Au}$. The conversion rates were the following: $85 \%$ with in situ (AR_is-75Au\&25Pt) and 90\% with impregnation (AR_im-75Au\&25Pt).

Overall, considering the two reduction methods, the following conclusions can be drawn:

- In situ method: for the P25 and AA-based composites, the best photocatalytic activity was achieved when the sequential reduction was used-first $\mathrm{Au}$ then $\mathrm{Pt}(\mathrm{Au} / \mathrm{Pt})$. For the AR-based composited the simultaneous reduction of the noble metals proved to be the best $(\mathrm{Au} \& \mathrm{Pt})$;

- Impregnation: for the P25-based composites, the sequential reduction was the best as well as for the other method (first $\mathrm{Pt}$ then $\mathrm{Au}-\mathrm{Pt} / \mathrm{Au}$ ). For the AR and AA-based catalysts, the simultaneous reduction of the nanoparticles proved to be the best according to oxalic acid degradation (Au\&Pt);

- Regarding the order of the reduction of the two noble metals:

- First $\mathrm{Au}$ then $\mathrm{Pt}(\mathrm{Au} / \mathrm{Pt})$ : when the base catalyst was AA or P25, using in situ reductions in both cases (AA_is-Au/Pt, P25_is- $\mathrm{Au} / \mathrm{Pt}$ );

- First $\mathrm{Pt}$ then $\mathrm{Au}(\mathrm{Pt} / \mathrm{Au})$ : when the base catalyst was the P25, using impregnation method (P25_im-Pt/Au);

- $\quad \mathrm{AU}$ and Pt at the same time (Au\&Pt): the AR-based composites (in situ and impregnation as well_-(AR_is-Au\&Pt, (AR_im-Au\&Pt) and AA-based ones, using impregnation (AA_im-Au\&Pt);

- The ratio between the noble metals: the change in the composition improved the photocatalytic activity only in the case of the AR-based composites.

Considering the degradation of carboxylic acids, such as oxalic acid, both gold and platinum nanoparticles deposited on the surface of titania are good photocatalysts: this is demonstrated by the experiments also, which can be seen in Figures 7 and 8. Overall, it is well-known that the synergistic effect between $\mathrm{Au}$ and $\mathrm{Pt}$ results in a significant enhancement in photocatalytic activity [35]. The mechanism lies within the transfer of the charge carriers from the noble metals to $\mathrm{TiO}_{2}$ [36]. The surface plasmon resonance (SPR) effect of the gold nanoparticles can increase the electron-hole formation rate [37]. Overall, this means the enhanced photocatalytic activity of the titania. The presence of both noble metals can result in different outcomes: they can be located separately, they can form core-shell structures or alloys [27]. If one nanoparticle is located on the other, the electron transfer path is longer. Therefore, more holes are available for oxidation [38]. This is why the ternary composites have better photocatalytic activity. 


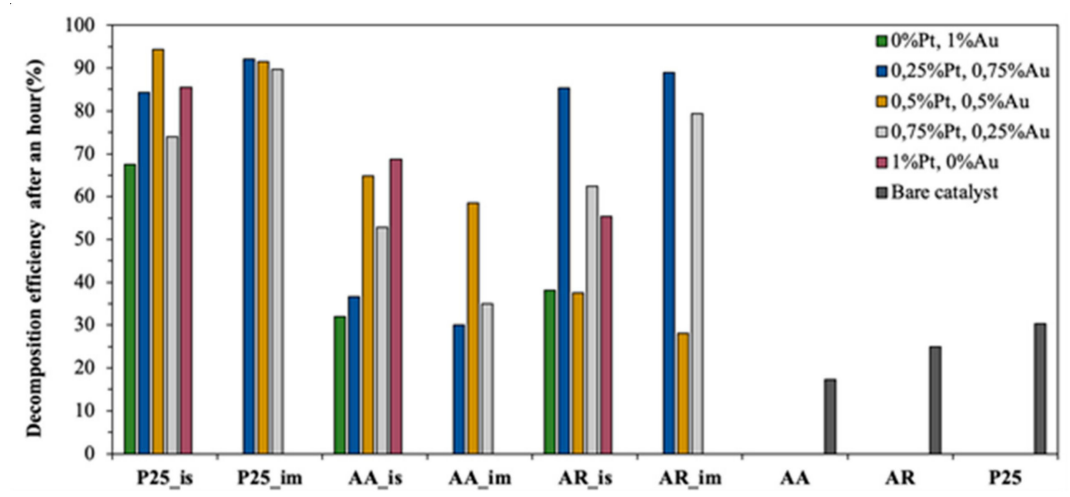

Figure 7. Decomposition efficiency for the degradation of oxalic acid after an hour.

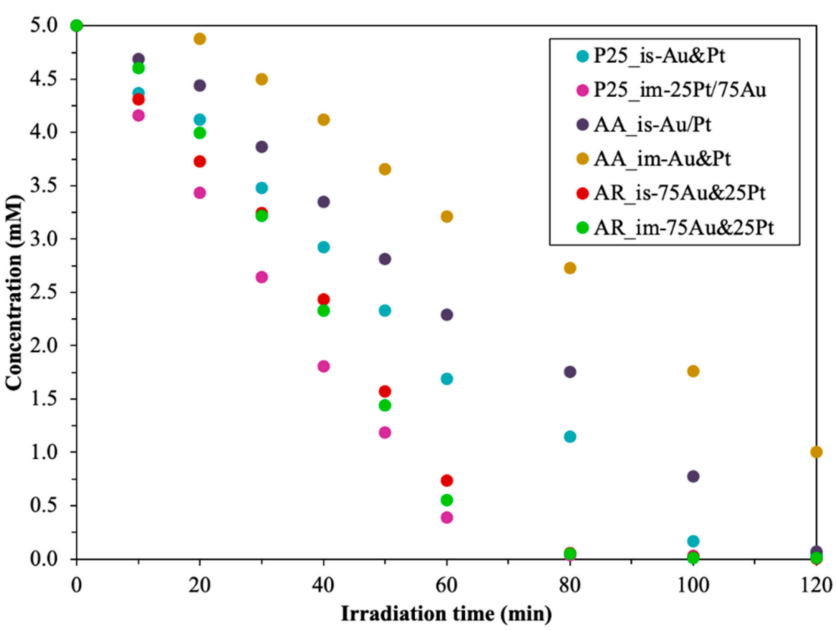

Figure 8. Degradation curves for oxalic acid—those composites are marked that had the best activity for each base catalyst (Evonik Aeroxide P25 (P25), Aldrich anatase (AA), Aldrich rutile (AR)).

\subsubsection{Photodegradation of Salicylic Acid}

Salicylic acid degradation experiments were performed on the composites that demonstrated the best photocatalytic activity on oxalic acid. This is also illustrated in Figure 8. For each of the base photocatalysts, one in situ and one impregnation-made composite was chosen for salicylic acid photodegradation. This is presented in Figure 9.

The ternary composites containing P25, Au and Pt (P25_is-Au/Pt-48\%, P25_im$\mathrm{Pt} / \mathrm{Au}-36 \%$ ) did not show better photocatalytic activity than the bare P25 (66.6\%). The composite obtained using in situ reduction showed better activity in the first hour, but in the second hour, the activity sequence changed. P25 reached $66.6 \%$ conversion at the end of the second hour, while the sample named P25_is-Au/Pt decomposed $48 \%$ of the salicylic acid. The P25_im-Pt/ Au composite showed even lower conversion. Only 36\% had been degraded from the salicylic acid.

In the second case, both (in situ and impregnated) composites achieved better photocatalytic activity than bare AA. The AA_is-Au/Pt composite decomposed the salicylic acid by $93 \%$ at the end of the two-hour experiment, and less than $0.05 \mathrm{mM}$ of salicylic acid remained in the system. The AA_im-Au\&Pt catalyst also achieved relatively high efficiency and decomposed $81 \%$ of salicylic acid, while bare AA reached a $40 \%$ conversion. 


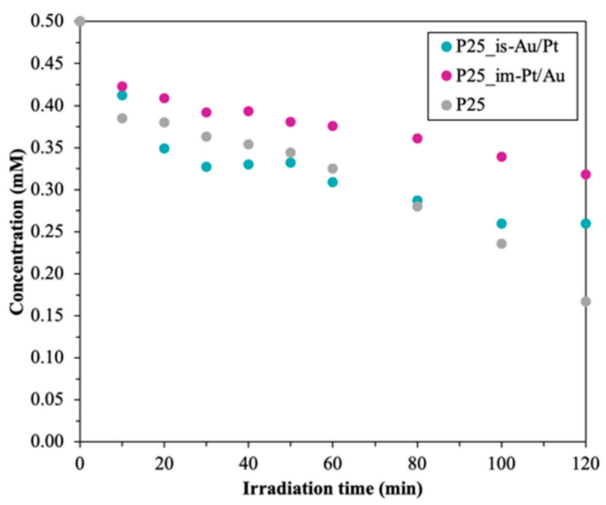

(a)

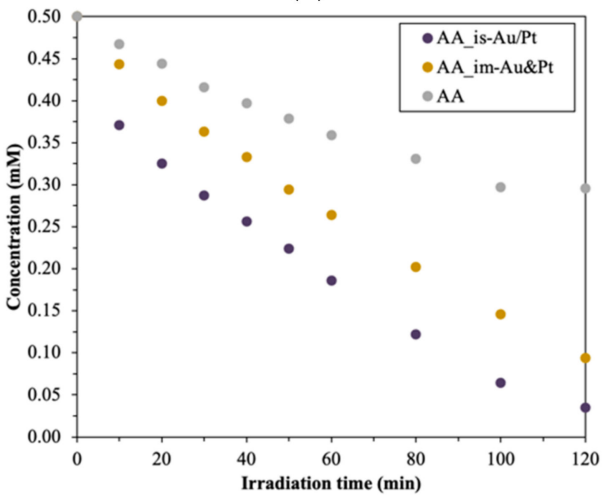

(b)

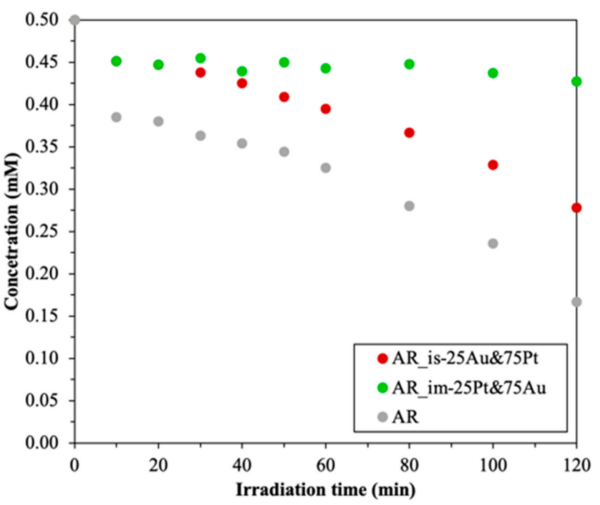

(c)

Figure 9. Degradation curves of salicylic acid-(a) P25 and it is composites, (b) AA and it is composites, and (c) AR, and it is composites-the AA-based composites achieved better photocatalytic activity than the base catalyst.

AR itself showed better activity on salicylic acid than its composites with gold and platinum. Simultaneously, the composite made with in situ reductions (AR_is25Au\&75Pt) showed better photocatalytic activity than the impregnated (AR_im-25Pt\&75Au) one. The AR_im-25Pt\&75Au sample proved to be almost inactive, as only $14 \%$ of salicylic acid was decomposed. The efficiency of bare AR was $66 \%$, which was approached by the AR_is25Au\&75Pt composite with a conversion value of $45 \%$.

Figure 10 illustrates the comparison of the degradation of oxalic acid and salicylic acid of the samples and the bare titanias. A general observation is that for the P25 and AR-based catalysts, the degradation of oxalic acid was much higher than the degradation of salicylic acid. There is only one exception, namely sample AA_im-Au\&Pt, where the photocatalytic activity (after an hour) was higher for salicylic acid (47.2\%) than for oxalic acid (25.4\%). The AA-based photocatalyst made with in situ method had almost the same decomposition 
efficiency for salicylic acid and oxalic acid with the values of $62.8 \%$ and $64.8 \%$. Interestingly, the unmodified titanias had better photocatalytic activity for the degradation of salicylic acid than for the oxalic acid.

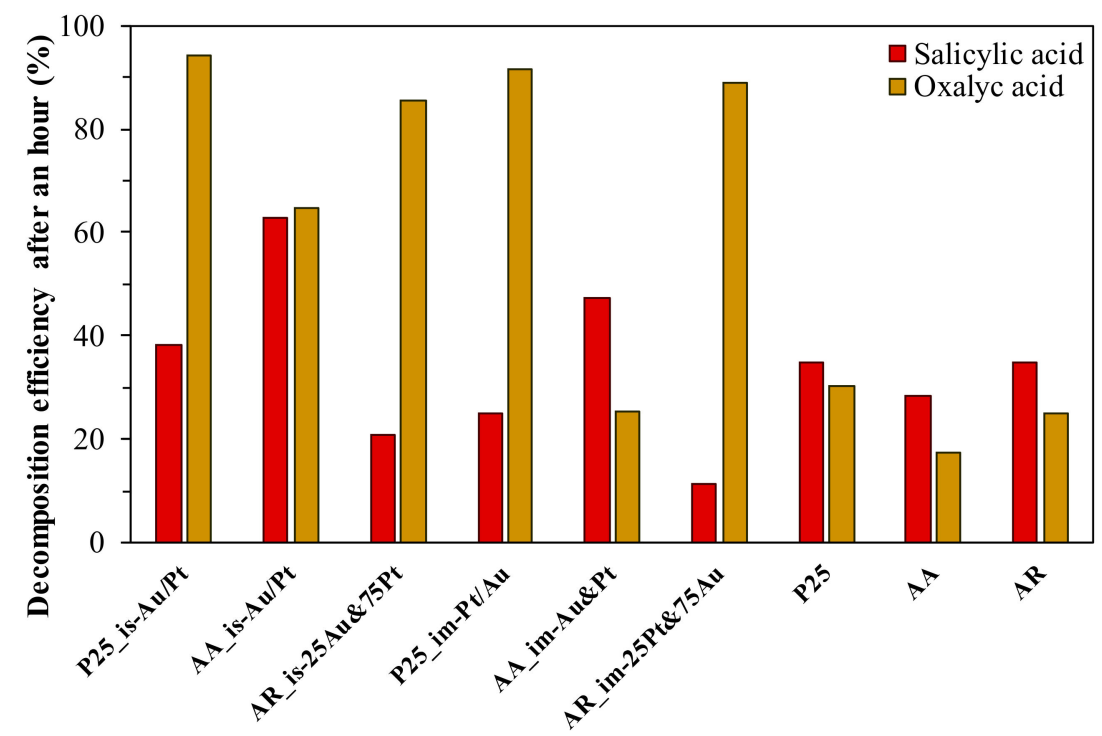

Figure 10. Comparison of the degradation of oxalic acid and salicylic acid of the samples-generally, the P25 and AR-based composites had higher activity for oxalic acid degradation than for salicylic acid.

As detailed in Section 3.4.1, the presence of noble metals is essential. During the degradation of salicylic acid, surface complexes are generated, so absorption has a big role here [39]. This process has an affinity for the surface of anatase titanias. This explains why only the AA-based composites achieved better activity than the base catalyst. The anatase phase plus the high specific surface area [40] of the AA contributed to the improved photocatalytic activity.

\subsubsection{Photocatalytic $\mathrm{H}_{2}$ Production}

Figure 11 presents the obtained volume of $\mathrm{H}_{2}$ during the experiments, expressed in $\mathrm{mL}$. In the case of P25-based catalysts after the changed concentration of the noble metals, the highest amount of hydrogen, $1800 \mu \mathrm{mol}$, was produced by the composite named P25_is-75Au/25Pt. For the impregnated composites (P25_im-Pt/Au), the change in the concentration did not increase the hydrogen production ability. The best sample remained, which contained $0.5 \% \mathrm{Au}$ and $0.5 \% \mathrm{Pt}\left(\mathrm{P} 25 \_\mathrm{im}-\mathrm{Pt} / \mathrm{Au}\right)$, producing $1600 \mu \mathrm{mol}$ of hydrogen.

The best AA-based photocatalysts were the in situ made AA_is- $\mathrm{Au} / \mathrm{Pt}$, which produced $1100 \mu \mathrm{mol}$ of hydrogen. Using the impregnation method, the reference catalyst containing only $\mathrm{Pt}\left(\mathrm{AA} \_\mathrm{im}-\mathrm{Pt}\right.$ ) produced $576 \mu \mathrm{mol} \mathrm{H} \mathrm{H}_{2}$. After this, AA_im-Au\&Pt, with the $200 \mu \mathrm{mol}$ of $\mathrm{H}_{2}$ production, proved to be the (second) best.

In the case of AR-based composites, the change of Au:Pt ratio did not show a beneficial effect. Using both reduction methods, that composite proved to be the best when the gold was reduced simultaneously with platinum at 0.5 to $0.5 \%$. With in situ reductions (AR_is-Au\&Pt) $650 \mu \mathrm{mol}$, with impregnation (AR_im-Au\&Pt), $600 \mu \mathrm{mol}$ of hydrogen was produced. If in situ reductions were used, the reference sample (AR_is-Pt) had a higher $\mathrm{H}_{2}$ production rate than the ternary composites with a value of $710 \mu \mathrm{mol}$. 


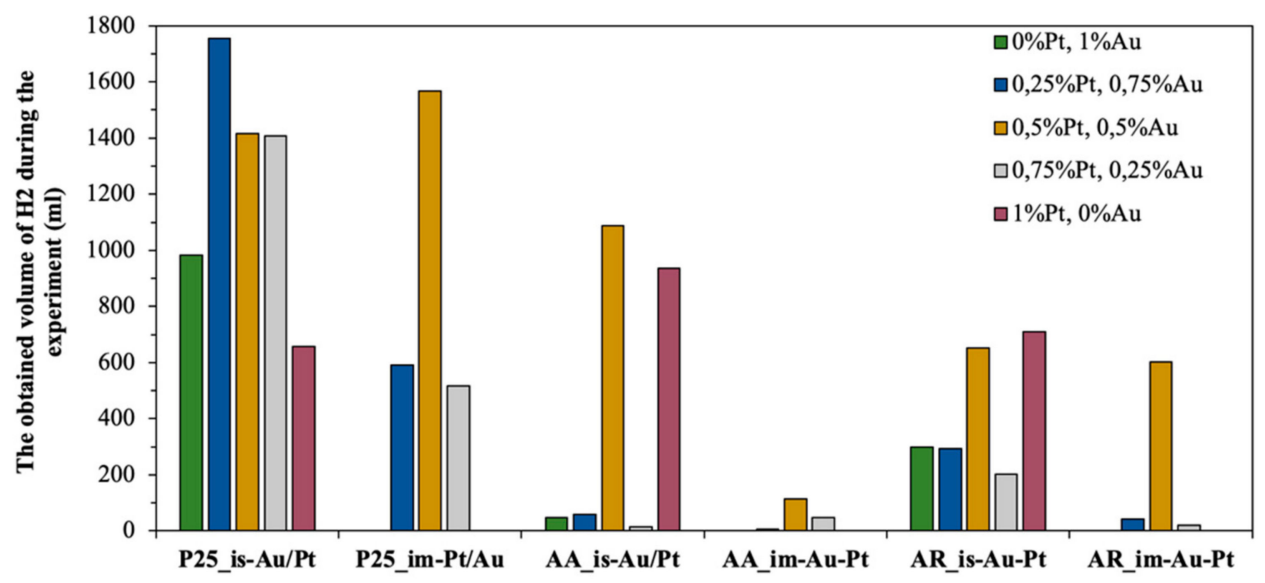

Figure 11. The obtained volume of $\mathrm{H}_{2}$ in $\mathrm{mL}$ after the two-hour experiments.

Figure 12 shows the time-resolved hydrogen production rates of the composites during the experiment. The best value of all the samples is from the P25 series, named P25_im$\mathrm{Pt} / \mathrm{Au}$. The weakest result was shown, in the same way as the oxalic acid degradation, by the AA composite, named AA_im-Au\&Pt.

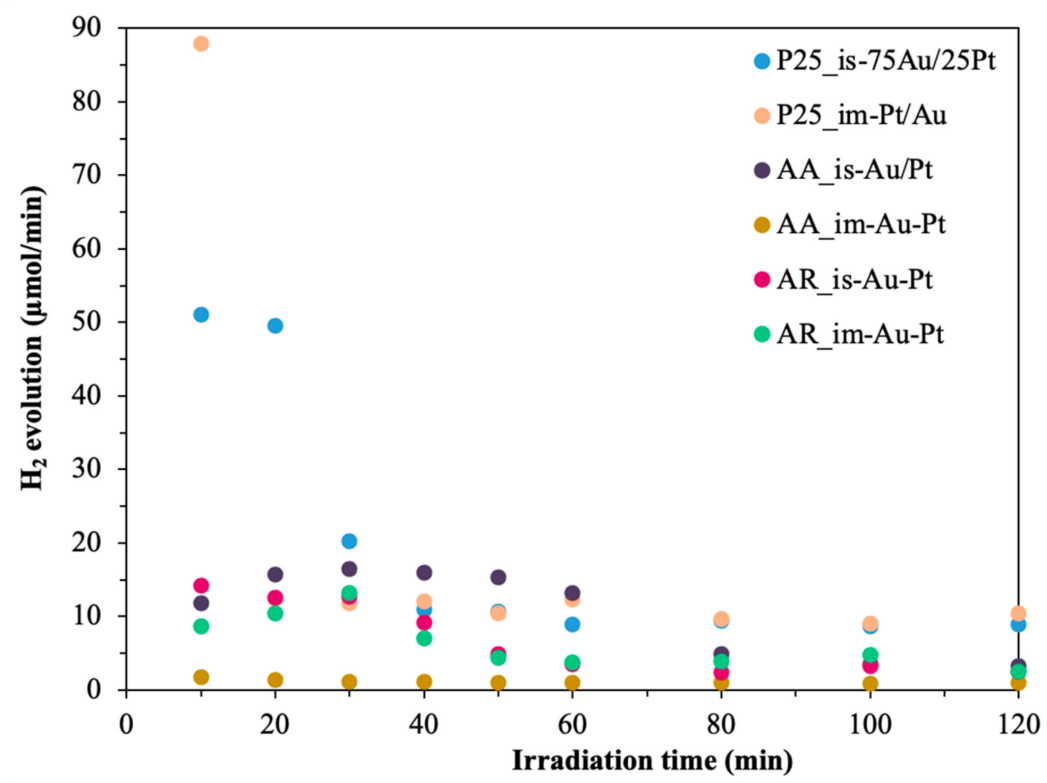

Figure 12. Time-resolved hydrogen production rates of the composites, which produced the most $\mathrm{H}_{2}$-the best value of all the samples is P25_im-Pt/ $\mathrm{Au}$.

It is a known fact that for hydrogen production, the presence of the platinum nanoparticles helps produce more $\mathrm{H}_{2}$ : this is demonstrated by the experiments also, which can be seen in Figure 11. As mentioned in Section 3.4.1, if the platinum is located on the surface of gold, there are more chances for hydrogen production. In addition, the high specific surface area and anatase phase is important here as well; that is why the P25-based catalysts produced the most $\mathrm{H}_{2}$.

\section{Conclusions}

In summary, three commercial titanias-Evonik Aeroxide P25, Aldrich rutile and Aldrich anatase-were combined with two noble metals: gold and platinum nanoparticles. The noble metal composition varies from 0.25 to $0.75 \%$ in each composite, where the remaining $99 \%$ is one of the above-mentioned commercial titania. 
After the preparation of the composites, their morphological and structural properties were investigated. From the XRD can be observed that the titanias composition remained unchanged during/after the deposition of noble metal nanoparticles. From the DRS measurements, it can be concluded that the presence of the noble metals decreased the bandgap energy, and TEM measurements confirmed that the particle sizes of the nanoparticles were between 1 and $4 \mathrm{~nm}$.

The photocatalytic activity and hydrogen production capacity was also investigated. For the oxalic acid degradation, the best photocatalyst was the one that was based on P25, made with in situ method when Au was first reduced then Pt (P25_is-Au/Pt). For the salicylic acid degradation, the best photocatalyst was the one that was based on AA, made with in situ method when Au was first reduced, then Pt (AA_is-Au/Pt). In addition to all, the hydrogen production capacity was investigated as well. The sacrificial agent was oxalic acid, and UV-light was used as well. The most $\mathrm{H} 2$ was produced by the P25 bases sample made with in situ reductions, when first $0.75 \% \mathrm{Au}$ then $0.25 \% \mathrm{Pt}$ was reduced (P25_is-75Au/25Pt).

Considering the ratio between the noble metals, the following observation can be made:

- In terms of the base catalyst, only in the case of the AR-based composites improved the photocatalytic activity the change in the composition for the oxalic acid degradation (AR_im-75Au\&25Pt);

- The hydrogen production capacity was improved only in the case of P25-based catalysts when the concentration of the noble metals was changed by the composite named P25_is-75Au/25Pt.

Author Contributions: Investigation, B.H.; conceptualization, B.H.; writing—original draft preparation, B.H.; writing—review and editing, K.H., Z.P., L.B.; supervision, Z.P.; funding acquisition, Z.P. All authors have read and agreed to the published version of the manuscript.

Funding: Zsolt Pap acknowledges the Bolyai János Research Scholarship received from the Hungarian Academy of Sciences. This study was financed by the NKFI-K-124212 project.

Informed Consent Statement: Not applicable.

Acknowledgments: There is no special activity to acknowledge.

Conflicts of Interest: The authors declare no conflict of interest.

\section{References}

1. Zhang, L.; Gu, F.; Chan, J.; Wang, A.; Langer, R.; Farokhzad, O. Nanoparticles in Medicine: Therapeutic Applications and Developments. Clin. Pharmacol. Ther. 2008, 83, 761-769. [CrossRef] [PubMed]

2. Schaming, D.; Remita, H. Nanotechnology: From the ancient time to nowadays. Found. Chem. 2015, 17, 187-205. [CrossRef]

3. Liu, H.; Song, C.; Zhang, L.; Zhang, J.; Wang, H.; Wilkinson, D.P. A review of anode catalysis in the direct methanol fuel cell. J. Power Sources 2006, 155, 95-110. [CrossRef]

4. Forster, S.P.; Olveira, S.; Seeger, S. Nanotechnology in the market: Promises and realities. Int. J. Nanotechnol. 2011, 8, 592-613. [CrossRef]

5. Siegrist, M.; Cousin, M.E.; Kastenholz, H.; Wiek, A. Public acceptance of nanotechnology foods and food packaging: The influence of affect and trust. Appetite 2007, 49, 459-466. [CrossRef] [PubMed]

6. Zhou, Q.; Xie, B.; Jin, L.; Chen, W.; Li, J. Hydrothermal Synthesis and Responsive Characteristics of Hierarchical Zinc Oxide Nanoflowers to Sulfur Dioxide. J. Nanotechnol. 2016, 2016. [CrossRef]

7. Zhang, W.X. Nanoscale iron particles for environmental remediation: An overview. J. Nanoparticle Res. 2003, 5, 323-332. [CrossRef]

8. Rasalingam, S.; Peng, R.; Koodali, R.T. Removal of hazardous pollutants from wastewaters: Applications of $\mathrm{TiO}_{2}-\mathrm{SiO}_{2}$ mixed oxide materials. J. Nanomater. 2014, 2014. [CrossRef]

9. Huang, L.; Peng, F.; Yu, H.; Wang, H. Preparation of cuprous oxides with different sizes and their behaviors of adsorption, visible-light driven photocatalysis and photocorrosion. Solid State Sci. 2009, 11, 129-138. [CrossRef]

10. Kim, J.; Lee, C.W.; Choi, W. Platinized $\mathrm{WO}_{3}$ as an environmental photocatalyst that generates $\mathrm{OH}$ radicals under visible light. Environ. Sci. Technol. 2010, 44, 6849-6854. [CrossRef]

11. Daneshvar, N.; Salari, D.; Khataee, A.R. Photocatalytic degradation of azo dye acid red 14 in water on $\mathrm{ZnO}$ as an alternative catalyst to $\mathrm{TiO}_{2}$. J. Photochem. Photobiol. A Chem. 2004, 162, 317-322. [CrossRef] 
12. Panudda, P.; Ekthammathat, N.; Phuruangrat, A.; Thongtem, S.; Thongtem, T. BiOX (X = Cl, Br, and I) Nanoplates Prepared by Surfactant-Free Microwave Synthesis and Their Photocatalytic Performance. Russ. J. Phys. Chem. A 2018, 92, $2289-2295$. [CrossRef]

13. Gaya, U.I.; Abdullah, A.H. Heterogeneous photocatalytic degradation of organic contaminants over titanium dioxide: A review of fundamentals, progress and problems. J. Photochem. Photobiol. C Photochem. Rev. 2008, 9, 1-12. [CrossRef]

14. El Rouby, W.M.A.; Comesaña-Hermo, M.; Testa-Anta, M.; Carbó-Argibay, E.; Salgueiriño, V.; Pérez-Lorenzo, M.; Correa-Duarte, M.A. Au-decorated sodium titanate nanotubes as high-performance selective photocatalysts for pollutant degradation. J. Phys. D Appl. Phys. 2017, 50. [CrossRef]

15. Dawson, A.; Kamat, P.V. Semiconductor-metal nanocomposites. Photoinduced fusion and photocatalysis of gold-capped TiO 2 ( $\mathrm{TiO}_{2} /$ Gold) nanoparticles. J. Phys. Chem. B 2001, 105, 960-966. [CrossRef]

16. Yu, C.; Cao, F.; Li, G.; Wei, R.; Yu, J.C.; Jin, R.; Fan, Q.; Wang, C. Novel noble metal (Rh, Pd, Pt)/BiOX (Cl, Br, I) composite photocatalysts with enhanced photocatalytic performance in dye degradation. Sep. Purif. Technol. 2013, 120, 110-122. [CrossRef]

17. Subramanian, V.; Wolf, E.E.; Kamat, P.V. Catalysis with $\mathrm{TiO}_{2} /$ Gold Nanocomposites. Effect of Metal Particle Size on the Fermi Level Equilibration. J. Am. Chem. Soc. 2004, 126, 4943-4950. [CrossRef]

18. Zhang, H.; Lv, X.; Li, Y.; Wang, Y.; Li, J. P25-graphene composite as a high performance photocatalyst. ACS Nano 2010, 4, 380-386. [CrossRef] [PubMed]

19. Wang, H.; He, X.; Zhou, B.; Shen, J.; Du, A. Hot electrons coupling-enhanced photocatalysis of super black carbon aerogels/titanium oxide composite. MRS Commun. 2018, 8, 521-526. [CrossRef]

20. Stroyuk, A.L.; Shvalagin, V.V.; Kuchmii, S.Y. Photochemical synthesis and optical properties of binary and ternary metalsemiconductor composites based on zinc oxide nanoparticles. J. Photochem. Photobiol. A Chem. 2005, 173, 185-194. [CrossRef]

21. Su, R.; Tiruvalam, R.; Logsdail, A.J.; He, Q.; Downing, C.A.; Jensen, M.T.; Dimitratos, N.; Kesavan, L.; Wells, P.P.; Bechstein, R.; et al. Designer titania-supported Au-Pd nanoparticles for efficient photocatalytic hydrogen production. ACS Nano 2014, 8 , 3490-3497. [CrossRef] [PubMed]

22. Arora, N.; Mehta, A.; Mishra, A.; Basu, S. 4-Nitrophenol reduction catalysed by Au-Ag bimetallic nanoparticles supported on LDH: Homogeneous vs. heterogeneous catalysis. Appl. Clay Sci. 2018, 151, 1-9. [CrossRef]

23. Chanu, I.; Krishnamurthi, P.; Manoharan, P.T. Effect of Silver on Plasmonic, Photocatalytic, and Cytotoxicity of Gold in AuAgZnO Nanocomposites. J. Phys. Chem. C 2017, 121, 9077-9088. [CrossRef]

24. Singh, S.; Srivastava, P.; Singh, G. Synthesis, characterization of Co-Ni-Cu trimetallic alloy nanocrystals and their catalytic properties, Part-91. J. Alloys Compd. 2013, 562, 150-155. [CrossRef]

25. Yan, W.; Tang, Z.; Wang, L.; Wang, Q.; Yang, H.; Chen, S. PdAu alloyed clusters supported by carbon nanosheets as efficient electrocatalysts for oxygen reduction. Int. J. Hydrog. Energy 2017, 42, 218-227. [CrossRef]

26. Henam Sylvia, D.; Henam Premananda, S.; Thiyam David, S. Green synthesized urchin like Pt/Cu bimetallic photonanocatalysts: Understanding composition effect. Mater. Res. Bull. 2017, 86, 277-286. [CrossRef]

27. Hampel, B.; Kovács, G.; Czekes, Z.; Hernádi, K.; Danciu, V.; Ersen, O.; Girleanu, M.; Focşan, M.; Baia, L.; Pap, Z. Mapping the Photocatalytic Activity and Ecotoxicology of $\mathrm{Au}, \mathrm{Pt} / \mathrm{TiO}_{2}$ Composite Photocatalysts. ACS Sustain. Chem. Eng. 2018, 6, 12993-13006. [CrossRef]

28. Kmetykó, Á.; Mogyorósi, K.; Pusztai, P.; Radu, T.; Kónya, Z.; Dombi, A.; Hernádi, K. Photocatalytic $\mathrm{H}_{2}$ evolution using different commercial $\mathrm{TiO}_{2}$ catalysts deposited with finely size-tailored au nanoparticles: Critical dependence on au particle size. Materials 2014, 7, 7615-7633. [CrossRef]

29. Scherrer, P. Bestimmung der Grosse und der inneren Struktur von Kolloidterilchen mittels Rontgestrahlen. In Nachrichten von der Gesellschaft der Wissenschaften zu Göttingen, Mathematisch-Physikalische Klasse; Weidmannsche Buchhandlung: Berlin, Germany, 1918; pp. 98-100.

30. Scarpelli, F.; Mastropietro, T.F.; Poerio, T.; Godbert, N. Mesoporous $\mathrm{TiO}_{2}$ Thin Films: State of the Art. In Titanium Dioxide—Material for a Sustainable Environment; Yang, D., Ed.; IntechOpen: London, UK, 2018. [CrossRef]

31. Kovács, G.; Fodor, S.; Vulpoi, A.; Schrantz, K.; Dombi, A.; Hernádi, K.; Danciu, V.; Pap, Z.; Baia, L. Polyhedral Pt vs. spherical Pt nanoparticles on commercial titanias: Is shape tailoring a guarantee of achieving high activity? J. Catal. 2015, 325, 156-167. [CrossRef]

32. Baia, L.; Vulpoi, A.; Radu, T.; Karácsonyi, É.; Dombi, A.; Hernádi, K.; Danciu, V.; Simon, S.; Norén, K.; Canton, S.E.; et al. $\mathrm{TiO}_{2} / \mathrm{WO}_{3} / \mathrm{Au}$ nanoarchitectures' photocatalytic activity "from degradation intermediates to catalysts" "structural peculiarities": Part II: Aerogel based composites-fine details by spectroscopic means. Appl. Catal. B Environ. 2014, 148-149, 589-600. [CrossRef]

33. Murphy, A.B. Band-gap determination from diffuse reflectance measurements of semiconductor films, and application to photoelectrochemical water-splitting. Sol. Energy Mater. Sol. Cells 2007, 91, 1326-1337. [CrossRef]

34. Ohtani, B.; Prieto-Mahaney, O.O.; Li, D.; Abe, R. What is Degussa (Evonic) P25? Crystalline composition analysis, reconstruction from isolated pure particles and photocatalytic activity test. J. Photochem. Photobiol. A Chem. 2010, 216, 179-182. [CrossRef]

35. Xue, J.; Ma, S.; Zhou, Y.; Zhang, Z.; He, M. Facile photochemical synthesis of $\mathrm{Au} / \mathrm{Pt} / \mathrm{g}-\mathrm{C}_{3} \mathrm{~N}_{4}$ with plasmon-enhanced photocatalytic activity for antibiotic degradation. ACS Appl. Mater. Interfaces 2015, 7, 9630-9637. [CrossRef] [PubMed]

36. Ribao, P.; Rivero, M.J.; Ortiz, I. $\mathrm{TiO}_{2}$ structures doped with noble metals and/or graphene oxide to improve the photocatalytic degradation of dichloroacetic acid. Environ. Sci. Pollut. Res. Int. 2017, 12628-12637. [CrossRef] 
37. Bian, Z.; Tachikawa, T.; Zhang, P.; Fujitsuka, M.; Majima, T. Au/ $\mathrm{TiO}_{2}$ superstructure-based plasmonic photocatalysts exhibiting efficient charge separation and unprecedented activity. J. Am. Chem. Soc. 2014, 136, 458-465. [CrossRef] [PubMed]

38. Zhang, L.; Mohamed, H.H.; Dillert, R.; Bahnemann, D. Kinetics and mechanisms of charge transfer processes in photocatalytic systems: A review. J. Photochem. Photobiol. C Photochem. Rev. 2012, 13, 263-276. [CrossRef]

39. Regazzoni, A.E.; Mandelbaum, P.; Matsuyoshi, M.; Schiller, S.; Bilmes, S.A.; Blesa, M.A. Adsorption and photooxidation of salicylic acid on titanium dioxide: A surface complexation description. Langmuir 1998, 14, 868-874. [CrossRef]

40. Guo, Q.; Zhou, C.; Ma, Z.; Yang, X. Fundamentals of $\mathrm{TiO}_{2}$ Photocatalysis: Concepts, Mechanisms, and Challenges. Adv. Mater. 2019, 31, 1-26. [CrossRef] [PubMed] 